\title{
Red cell transfusion in outpatients with myelodysplastic syndromes: a feasibility and exploratory randomized trial
}

Simon J Stanworth, DPhil, FRCP ${ }^{1,2,3}$, Sally Killick, $\mathrm{MD}^{4}$, Zoe McQuilten, $\mathrm{MD}^{5}$, Marina Karakantza, MD ${ }^{6}$, Robert Weinkove, MBBS, PhD ${ }^{9}$ Heather Smethurst, RSCN RGN ${ }^{7}$, Laura A Pankhurst, M.Sc ${ }^{8}$, Renate L Hodge, B.Sc, M.Sc ${ }^{7}$, Valerie Hopkins, B.Sc ${ }^{7}$, Helen L Thomas, M.Sc ${ }^{8}$, Alison J Deary, M.Sc ${ }^{7}$, Jeannie Callum, MD ${ }^{14,15}$, Yulia Lin, $\mathrm{MD}^{14,15}$, Erica Wood ${ }^{5}, \mathrm{MD}$, Rena Buckstein, MD, FRCPC ${ }^{12,13}$, and David Bowen, $\mathrm{MD}^{18}$, On behalf of the REDDS investigators

${ }^{1}$ Oxford University, Oxford, United Kingdom; ${ }^{2}$ The John Radcliffe Hospital, Oxford, GBR; ${ }^{3}$ NHSBT, Oxford, United Kingdom; ${ }^{4}$ The Royal Bournemouth and Christchurch Hospitals NHS Foundation Trust, Bournemouth, United Kingdom; ${ }^{5}$ Transfusion Research Unit, Monash University, Melbourne, Australia; ${ }^{6}$ Leeds Teaching Hospitals NHS Trust, Leeds, United Kingdom; ${ }^{7} \mathrm{NHS}$ Blood and Transplant Clinical Trials Unit, Cambridge, United Kingdom; ${ }^{8} \mathrm{NHS}$ Blood and Transplant Clinical Trials Unit, Bristol, United Kingdom; ${ }^{9}$ Wellington Blood \& Cancer Centre, Capital \& Coast District Health Board, Wellington, New Zealand; Malaghan Institute of Medical Research, Wellington, New Zealand; ${ }^{12}$ Odette Cancer Centre, Sunnybrook Health Sciences Centre, Toronto, ON, Canada; ${ }^{13}$ Sunnybrook Health Sciences, Odette Cancer Centre, University of Toronto, Toronto, ON, Canada; ${ }^{14}$ Department of Laboratory Medicine and Molecular Diagnostics, Sunnybrook Health Sciences Centre, Toronto, ON, Canada; ${ }^{15}$ Department of Laboratory Medicine and Pathobiology, University of Toronto, Toronto, ON, Canada; ${ }^{18}$ Department of Haematology, Leeds Teaching Hospitals, Leeds, United Kingdom

\section{Corresponding author:}

Professor Simon J Stanworth

Consultant Haematologist

NHS Blood and Transplant/

Oxford University Hospitals NHS Foundation Trust

Level 2, John Radcliffe Hospital

Headley Way

Oxford. OX3 9BQ

Simon.stanworth@nhsbt.nhs.uk

441865387976

Running head: Optimizing transfusion in myelodysplasia

Word counts for text and abstract, 3800; 199

Figure/table count: 2 tables, 4 figures 


\section{Abstract}

Optimal red cell transfusion support in myelodysplastic syndromes (MDS) has not been tested and established. The aim of this study was to demonstrate feasibility of recruitment and follow-up in an out-patient setting with an exploratory assessment of Quality of Life (QoL) outcomes (EORTC QLQC30 and EQ-5D-5L).

We randomised MDS patients to standardized transfusion algorithms comparing current restrictive transfusion thresholds $(80 \mathrm{~g} / \mathrm{L}$, to maintain haemoglobin $85-100 \mathrm{~g} / \mathrm{L})$ with liberal thresholds $(105 \mathrm{~g} / \mathrm{L}$, maintaining $110-125 \mathrm{~g} / \mathrm{L}$ ). The primary outcomes were measures of compliance to transfusion thresholds.

38 patients were randomized ( $n=20$ restrictive; $n=18$ liberal) from 12 participating sites in UK, Australia, New Zealand. The compliance proportion for the intention-to-treat population was $86 \%$ (95\% confidence interval 75\%-94\%) and 99\% (95\%-100\%) for restrictive and liberal arms, respectively. Mean pre-transfusion haemoglobin concentrations for restrictive and liberal arms were $80 \mathrm{~g} / \mathrm{L}$ (SD6) and 97g/L (SD7). The total number of red cell units transfused on study was 82 in the restrictive and 192 in the liberal arm. In an exploratory analysis, the five main QoL domains were improved for participants in the liberal compared to restrictive arm.

Our findings support the feasibility and need for a definitive trial to evaluate the effect of different red cell transfusion thresholds on patient-centred outcomes. 


\section{Introduction}

Myelodysplastic syndromes (MDS) are heterogeneous malignant myeloid stem cell disorders (Cogle et al, 2011). The incidence of MDS is rising as life-expectancy continues to rise and following diagnosis most MDS patients will become red cell transfusion dependent (Sekeres et al, 2008). Red cell transfusion dependency is associated with decreased overall and leukaemia-free survival in MDS, independent of cytogenetic risk groups, and with a reduced quality of life (QoL) (Malcovati et al, 2011; de Swart et al, 2019; Jadersten et al, 2005). The European MDS (EUMDS) Registry program has also demonstrated inferior QoL and decreased health utility in transfusion-dependent compared with transfusion-independent patients (Stauder et al, 2018). Although haemoglobin concentration is reported to have the greatest impact on QoL in MDS patient (Stauder et al, 2018), optimal transfusion support in MDS has not been established and it remains unclear whether different red cell transfusion policies would modify clinical outcomes, QoL and functional measures. Lower haemoglobin concentrations may simply be surrogates for more advanced disease, with inferior QoL scores attributable to other disease manifestations (like infections or bleeding) and not to lower haemoglobin values per se.

A typical haemoglobin concentration used clinically to guide red cell transfusion thresholds in MDS is around $80 \mathrm{~g} / \mathrm{L}$, as described by results from a UK national audit (https://hospital.blood.co.uk /audits/national-comparative-audit/) and a survey in Australasia (Mo et al, 2017). The EUMDS registry found the most common threshold across Europe to be $80 \mathrm{~g} / \mathrm{L}$, although this varied from country to country (data across the 21 EUMDS centres in the UK indicated a mean of $84 \mathrm{~g} / \mathrm{L}$ ) (Stauder et $a l, 2018)$. These thresholds for red cell transfusion acknowledge the general goals of transfusion which are to minimize exposure to blood as a biological agent with risks, and to transfuse only at lower haemoglobin thresholds to prevent serious complications like congestive heart failure. In some settings including cardiac disease, higher transfusion thresholds may be beneficial (Docherty et al, 2016), but no strategy for red cell transfusion has been tested in clinical trials in MDS, and restrictive thresholds may come at the cost of reduced physical function and increased symptoms of fatigue and dyspnoea (Buckstein et al, 2011). Data from trials comparing different transfusion thresholds in transfusion-dependent outpatients with MDS are essential to define an optimal policy for red cell transfusion and hence the 'standard of care' against which the benefits of new diseasemodifying therapies in MDS would be established."

Although randomized trials have been conducted in patients with acute critical illness anaemia, there are no completed trials in the outpatient setting for transfusion-dependent patients (Carson et 
al, 2018), and little data in general about the value of outpatient transfusions (Lin et al, 2019). Before embarking on multi-centre randomized controlled trials to definitively define optimal transfusion policies, we aimed to demonstrate feasibility of recruitment and follow-up in an outpatient setting for an elderly patient population, and with an assessment of implementation and adherence to a standardized transfusion protocol (both nationally and internationally). We aimed to compare a typical current restrictive red cell transfusion threshold with a liberal threshold that maintains a higher haemoglobin concentration, which may be associated with improved function and QoL, given emerging data that a haemoglobin concentration level of $\geq 100 \mathrm{~g} / \mathrm{L}$ appears to be a key threshold for improvement in functioning and symptom scores (Buckstein et al, 2011).

\section{Methods}

\section{Selection of sites and participants}

Investigators and clinical trial sites were selected based on clinical and research interests in the target population, and support from local hospital transfusion services. Patients were eligible for enrolment if they fulfilled the following inclusion criteria: 1) A diagnosis of MDS based on the WHO criteria (Swerdlow et al, 2008), $\geq 18$ years of age and $<20 \%$ blasts on bone marrow aspirate, including non-proliferative CMML and other MDS/MPN overlap diseases; 2) transfusion dependent, defined as at least 1 red cell transfusion episode per month in the last 8 weeks; and 3) life expectancy $>6$ months. Exclusion criteria were: 1$)$ Unable, in the opinion of the attending clinician, to tolerate restrictive or liberal red cell transfusion thresholds (e.g. clinically significant cardiorespiratory compromise) or clinically significant bleeding or haemolysis (defined pragmatically by clinicians); 2) Poor performance/functional status (Eastern Cooperative Oncology Group system ECOG $\geq 3$ ); 3) Treatment with erythropoiesis stimulating agents (ESAs) or disease-modifying agents for their MDS (as use of these agents would complicate the analysis of the effect of the transfusion intervention); 4) Patients with idiopathic myelofibrosis or clinical splenomegaly ( $>5 \mathrm{~cm}$ below the costal margin).

\section{Randomization and masking}

Following screening, and after the patient was consented following informed discussion, patients were transfused red cells to achieve a haemoglobin concentration of at least $100 \mathrm{~g} / \mathrm{L}$ during a sixweek run-in period. The study coordinator randomized the patient to the liberal or restrictive arms using sealed opaque envelopes. A computer-generated randomization schedule was prepared centrally by the study statistician, which was of a stratified block design. The schedule was stratified by centre with block sizes of 2 and 4 , and the allocation to treatment groups was a 1:1 ratio. The 
opaque sealed envelopes for each site were prepared from the schedule by an independent member of the clinical trials unit. Envelopes were opened in sequential number order. Patients were blinded to treatment arm and haemoglobin, but not to transfusions; investigators and clinicians were unblinded to treatment allocation.

\section{Transfusion policies (Figure 1)}

Two red cell transfusion strategies were applied for the 12 -week study period (day 0 to day 84 ). Day 0 represented the date of randomization and Day 7 the first clinic visit to implement the allocated transfusion algorithm. Participants were randomized to either:

1. Restrictive transfusion strategy to maintain haemoglobin concentration between 85 and $100 \mathrm{~g} / \mathrm{L}$, where 2 units of red cells were transfused when the haemoglobin concentration was $\leq 79 \mathrm{~g} / \mathrm{L}$ and 1 unit of red cells when the haemoglobin concentration was $80-85 \mathrm{~g} / \mathrm{L}$ inclusive.

2. Liberal transfusion strategy to maintain the haemoglobin concentration between 110 and $125 \mathrm{~g} / \mathrm{L}$, where 2 units of red cells were transfused when haemoglobin concentration was $\leq 104 \mathrm{~g} / \mathrm{L}$ and 1 unit of red cells when haemoglobin concentration was $105-110 \mathrm{~g} / \mathrm{L}$ inclusive.

The dose of red cells to be transfused and the schedule for clinic attendance were directed by the red cell transfusion algorithm, specifically created for this trial (Figure 1). Red cell transfusions were given within 3 days of the laboratory results for haemoglobin concentrations. A follow-up visit was scheduled in 1 week if the patient had pre-transfusion haemoglobin of $<70 \mathrm{~g} / \mathrm{l}$ in the restrictive, or $<$ $95 \mathrm{~g} / \mathrm{L}$ in the liberal arm. Otherwise, the algorithm mandated follow-up in 2 weeks. Transfusion of red cells outside the assigned red cell transfusion threshold was permitted if clinically indicated at the treating physician's discretion (e.g. severe bleeding, or if the haemoglobin was significantly below the minimal threshold). If admitted for in-patient care, patients would continue to be transfused as per their assigned strategy. Reasons for additional transfusions, inconsistencies or deviations from protocol adherence were documented.

Red cells (leucocyte-depleted, in additive solution, SAG-M: saline adenine glucose mannitol), conformed to standard national specifications similar between Australia, UK and New Zealand. The red cell units were requested from the hospital transfusion laboratory in accordance with local hospital procedures.

\section{Data Collection and quality of life}


Data collection was the responsibility of the local clinical team, principal investigator and research personnel. Data was recorded on paper-based case report forms (CRFs). The trial database was designed on MACRO ${ }^{\mathrm{TM}}$, a clinical trial data management system, by the CTU Data Management team and hosted securely within NHS Blood and Transplant (NHSBT). Data were entered into the trial database centrally by CTU staff and verified at site monitoring visits.

Participant characteristics collected at the time of informed consent included: participant age and sex, WHO diagnosis, date of diagnosis, results of full blood counts and bone marrow assessments, a record of baseline haemoglobin concentrations 2-5 years prior to diagnosis of MDS (if available), duration of dependence on red cell transfusions and history of iron chelation therapy. Data collected at later scheduled trial visits included clinical assessment (relevant medical history), dose of transfused red cells, haemoglobin concentration, ferritin, markers of liver function, and serious adverse events (SAEs). The EORTC QLQ-C30 and EQ-5D-5L were used to collect pre-transfusion (presumed nadir haemoglobin concentration) and one-week post transfusion QoL data to assess longitudinal changes related to red cell transfusion. Appropriate permission from the owners of these questionnaires was obtained. Maintenance of blinding was assessed during the trial as one of the study sub-objectives by asking "Which arm of the study do you think you are in?" at day 28 (week 4), day 56 (week 8) and day 84 (week 12).

\section{Safety Reporting}

As this was a trial using red cells, adverse events related to transfusion were collected, in addition to standard reporting of adverse events. Acute transfusion reactions to red cell blood components were defined as described in Serious Hazards Of Transfusion (SHOT, https://www.shotuk.org/). Serious Adverse Events (SAEs) were defined as: hospitalization, admission to intensive care unit, severe sepsis, disease progression, major organ dysfunction (single or multi-organ), transient ischemic attack, thromboembolic and ischemic events, as per CTCAE definitions.

\section{Outcomes}

The primary outcomes of this feasibility study, from day 0 to day 84 , were:

- The percentage of pre-transfusion haemoglobin concentrations below the target range of the assigned red cell transfusion strategy ('compliance to treatment threshold')

- Achievement of at least a $20 \mathrm{~g} / \mathrm{L}$ difference between the mean pre-transfusion haemoglobins in the liberal and restrictive strategy groups 
We pre-defined that we would consider this study feasible and would consider further development into a larger randomized trial if 'compliance to treatment threshold' was $\geq 70 \%$ in both arms, with evidence that a difference in haemoglobin concentrations in the liberal and restrictive strategy groups was achieved.

Secondary outcomes included: Number of patients ineligible, enrolment rates, proportion of transfusions given correctly according to algorithm, percentage compliance with completing the QoL questionnaires pre-transfusion and one week after transfusion, magnitude of changes in QoL, ability of patients to remain blinded to the treatment arm, overall utilization of blood, and numbers of adverse events including those potentially related to the transfusion threshold such as cardiac ischemic events, congestive heart failure, cerebrovascular accidents, thromboembolic or syncopal events.

\section{Statistical Considerations}

We proposed a sample size of 38 evaluable patients (19 patients each arm) to determine feasibility. This was guided by differences and standard deviations from data in a Cochrane systematic review of red cell transfusion thresholds (Carson et al, 2012). Power calculations based on a two-sided ttest, and a significance level (alpha) of 0.05 , indicated that a sample size of 17 patients per arm would have $80 \%$ power to detect a $20 \mathrm{~g} / \mathrm{L}$ difference between the two transfusion strategies. After allowing for a dropout rate of $10 \%$, the total sample size was 38 , with an equal distribution between treatment arms.

The main analysis was intention to treat (ITT). The primary outcomes and two secondary outcomes (percentages of pre-transfusion haemoglobin concentrations falling below, within and above the target range of the red cell transfusion threshold assigned and magnitude of change of scores for QoL) were replicated per-protocol. The per protocol (PP) analysis excluded those participants who were randomized in error or were not compliant with the threshold, which was defined as: any transfusions received when their haemoglobin had not dropped below the threshold, or who did not receive transfusions when their haemoglobin did drop below the threshold ( $85 \mathrm{~g} / \mathrm{L}$ restrictive arm or $110 \mathrm{~g} / \mathrm{L}$ liberal arm).

Primary and secondary outcomes were presented by treatment arm as numbers, percentages, means and medians, with exact 95\% confidence intervals, standard deviations and interquartile ranges (IQR), as appropriate. As this was a feasibility study powered only to detect a difference between treatment arms in the mean pre-transfusion haemoglobin, statistical testing was 
performed for the primary outcomes only and no other statistical testing or modelling was conducted. A p-value of less than 0.05 was considered to be statistically significant. SAS version 9.4 was used to conduct analyses.

For the primary outcome, the percentage compliance of pre-transfusion haemoglobin concentrations being below the target range of the red cell transfusion threshold assigned was presented by allocation arm, with an exact $95 \%$ confidence interval. The mean pre-transfusion haemoglobin level for each participant was calculated over the 12-week period, then two overall means were calculated for the restrictive and liberal groups, and the difference (with 95\% confidence interval) compared using a t-test. The mean difference and $95 \%$ confidence interval were used to assess whether a pre-specified $20 \mathrm{~g} / \mathrm{L}$ difference between the arms was achieved. An additional post-hoc analysis (adjusted sum of squares) was undertaken to explore the variation in amplitude of haemoglobin measurements per participant for those in the restrictive arm compared to the liberal arm.

The minimum number for QoL analysis was defined as a completed QoL questionnaire before the first trial transfusion after randomization (treated as baseline) and at least one other questionnaire, both of which were of the same type (either both EORTC QLQ-C30 or EQ-5D-5L). Scores on the EORTC questionnaire range between 0 and 100. For the descriptive part of EQ-5D-5L, index values were calculated (van Nout et al, 2012) to give a single score that ranges from -0.594 to 1 . The median and interquartile range of EQ-5D and EORTC QLQ-C30 scores for each arm were calculated. In addition to aggregate data, the percentages of patients individually achieving a clinically meaningful improvement, at any time point, compared to the baseline score, in each of the two strategies are presented. For this trial, clinically meaningful differences were pre-defined for the QLQ-C30 and EQ-5D as 10 and 0.08 points respectively (Maringwa et al, 2011; Luo et al, 2010; Cocks et al, 2011). In a post-hoc analysis, the standardized area under the curve (SAUC) was assessed for the key QoL outcomes, which allowed the longitudinal measurements per participant to be summarized.

\section{Governance and ethical approvals}

This study (ISRCTN26088319) was undertaken according to the Declaration of Helsinki and Good Clinical Practice principles. The protocol was approved by independent ethics committees in the UK (REC: 14/SC/1150), New Zealand (15/NTA/218) and Australia (HREC/15/MonH/144).. An 
independent data monitoring committee reviewed the data analysis and monitored patient safety by reviewing data every 6 months.

\section{Role of funding source}

The sponsor and funders had no role in the collection, analysis and interpretation of data, the writing of the report or the decision to submit

\section{Results}

\section{Patient recruitment and baseline characteristics}

38 patients were randomized from 12 hospitals ( $n=20$ restrictive; $n=18$ liberal) at participating sites in UK, Australia and New Zealand between February 2015 - July 2017. The proportion of patients screened and randomized is summarized in the CONSORT diagram (Figure 2). Two patients were randomized in error as not red cell transfusion dependent by the protocol definition, but both were included in the intention to treat analyses. The median number of participants randomized per month was 1 (IQR 1-2). The median age of randomized patients was 79 years (IQR 69-82). Although generally well matched, there were minor imbalances in baseline characteristics between arms (ECOG status, WHO subtype, prior iron chelation and heart failure medication; Table I)

\section{Primary outcome: haemoglobin}

Pre-transfusion haemoglobin concentrations from all randomized participants who had received any transfusions were included in the 'compliance to treatment threshold' analysis (34 participants in the ITT population). The percentage compliance and exact 95\% confidence intervals for the intention to treat population were $86 \%$ (75\%-94\%) and 99\% (95\%-100\%) for the restrictive and liberal arms respectively. As compliance was $\geq 70 \%$ in both arms, the study was declared feasible.

The mean (standard deviation) pre-transfusion haemoglobin concentration for the restrictive and liberal arms were 80 (6) g/L and 97 (7) g/L for the ITT population. The t-test was highly significant for both ITT and PP analyses $(p<0.0001)$ indicating a difference in the mean pre-transfusion haemoglobins between the two arms of the trial. The difference in mean pre-transfusion haemoglobins between arms for the ITT population was $16.7 \mathrm{~g} / \mathrm{L}$, with a $95 \%$ confidence interval of 14.6-18.8. Figure 3 shows the mean ( $\pm S D$ ) haemoglobin by week for all randomized participants by treatment arm. 
To assess the degree of fluctuation in haemoglobin concentration, the variation in amplitude of haemoglobin measurements for each participant relative to their own mean haemoglobin was computed (adjusted sum of squares; post-hoc analysis). There was greater variation in amplitude of haemoglobin measurements per participant for patients in the restrictive arm (median 72, IQR 47116) compared to the liberal arm (median 34, IQR 32-58).

\section{Use of red cells}

The total number of red cell units transfused on study, and total transfused after randomization, was 82 and 58 in the restrictive group and 192 and 105, respectively, in the liberal group. The median number of RBC units transfused per participant overall was 8 (IQR 5-11); with a median of 6 (IQR 47) in the restrictive arm and 11 (IQR 8-14) in the liberal arm. The median number of red cell units transfused for each participant per 4 weeks after the haemoglobin concentration first dropped below the threshold for transfusion was 3 (IQR 3-4) overall, with a median of 3 (IQR 2-3) in the restrictive arm and 4 (IQR 3-5) in the liberal arm. A graphical plot to illustrate the timing and volume of all red cell transfusions is shown in Figure 4. The median number of days between transfusions was 14 (IQR 11-21) in the restrictive arm and 14 (IQR 7-14) in the liberal arm, with a shift towards a shorter transfusion interval in the liberal arm.

\section{Protocol deviations and per-protocol analyses}

We defined strict measures of compliance in this first trial in an out-patient setting, and identified that the majority of patients in both arms deviated at some point from the protocol algorithm when assessed by threshold, dose and timing of transfusion for all reasons (although there was evidence of a significant difference in haemoglobin concentration attained between arms as described above). The overall number of transfusions given exactly according to the protocol (for threshold, dose and timing) was 19 (33\%) in the restrictive arm and 66 (63\%) in the liberal arm. Where a reason was specified for transfusing outside the algorithm, the most commonly stated reasons were participant symptoms (more common in the restrictive arm), holiday plans and other clinical discretion. A per protocol analysis of patients indicated a mean (standard deviation) pre-transfusion haemoglobin concentration for the restrictive and liberal arms at 80 (5) and 97 (7) respectively (10 patients). The difference in mean pre-transfusion haemoglobins between arms for the 'per-protocol' population was $17.1 \mathrm{~g} / \mathrm{L}$, with a 95\% confidence interval of 12.1-22.1.

\section{Quality of life and blinding}

Completion rate for EQ-5D-5L and EORTC QLQ-C30 questionnaires was high (70 - 80\%). The number of participants achieving a (pre-defined) clinically meaningful increase showed small improvements 
favouring the liberal policy across the following domains (EQ-5D-5L descriptive; EORTC QLQ-C30: fatigue and global health score). For example, for the fatigue domain, 9 participants (50\%) showed an improvement in the liberal arm compared to $5(30 \%)$ in the restrictive arm. In a post-hoc analysis the SAUC indicated that all five main QoL outcomes were improved for participants recruited in the liberal arm compared to the restrictive arm (see Table II).

Blinding of participants is an important determinant of interpretation of QoL. Blinding appeared to be well maintained, such that less than a third of participants correctly guessed their treatment arm at all three time points during the trial: $10 / 36(28 \%), 9 / 34(26 \%)$, and $9 / 32(28 \%)$ at day 28 , day 56 and day 84 .

\section{Safety and other outcomes}

Of 8 serious adverse events reported, 1 was deemed potentially related to transfusion (heart failure, restrictive arm) although this patient had multiple additional co-morbidities.

\section{Discussion}

In this feasibility randomized trial, we successfully recruited an older out-patient-based MDS population and applied different red cell thresholds for transfusion, meeting our primary feasibility outcome of at least $70 \%$ of transfusions with pre-transfusion haemoglobin below the target range. There was evidence of significant separation in mean haemoglobin (of $16.7 \mathrm{~g} / \mathrm{L}$ ) between treatment arms. Taken together, our findings support the feasibility of a definitive trial to evaluate the effect of different red cell transfusion thresholds on patient-centred outcomes.

Our results suggest that aiming for a higher haemoglobin concentration will require significantly more transfusions to maintain that level. The difference in units transfused between the two arms (Figure 4) challenges the perceived dogma that once a certain level of haemoglobin is attained, the red cell requirement will be broadly similar irrespective of haemoglobin. In a study using human growth factors and/or red cell transfusions to increase haemoglobin, the Nordic group (Nilsson-Ehle et al, 2011) authors demonstrated that patients who were transfusion dependent at study entry did not appear to require significantly more red cell transfusions to maintain the higher target haemoglobin concentration than during the pre-study period. Our findings on red cell usage also mandate the need for a cost-effectiveness component in any follow-on trials. 
Important learning points were addressed during our assessment of the feasibility and applicability of this algorithm. There are challenges achieving strict compliance with a transfusion protocol in an out-patient setting, and adequate funding (more than we had in this pilot study) is necessary to address full trial support including prospective monitoring of the transfusion algorithm and review of reasons for non-compliance. In our first trial in an out-patient setting we defined strict criteria for assessing compliance, and these reasons for non-compliance were varied. Nevertheless, overall, we still identified significant difference in haemoglobin concentrations between arms for recruitment across multiple sites including internationally. The small number of patients recruited at each site likely reflects a limited pool of potentially eligible transfusion-dependent patients at hospitals as well as the challenges of recruitment in an elderly population some of whom may not wish to consider changes to their established transfusion schedule. For these reasons, recruitment was extended to new sites after the start of the trial and this indicates the need for national and international collaboration in larger trials.

Although exploratory, there were a number of suggestions in our findings that higher haemoglobin thresholds might be associated with improved QoL, including the area under the curve analyses (Jasnsen et al, 2003). This finding is consistent with a very recent prospective observational study in which use of red cell transfusion was linked to modest benefits for measures such as a walk test and fatigue scores in a cohort of haematology/oncology outpatients (Lezin et al, 2019). Our results support the need to consider not just haemoglobin concentration, but also the magnitude of deviation in haemoglobin concentration, as demonstrated in our analysis of sum of squares. These QoL findings may have their basis in the smoother trajectory of haemoglobin concentrations with more liberal transfusion policies and appear consistent with an earlier modelling analysis reported by Caocci and colleagues (Caocci et al, 2007). Hellstrom-Lindberg have also evaluated QoL in anaemic patients with MDS receiving ESAs, using the EORTC QLQ-C30 (Hellstrom-Lindberg et al, 2003). These authors demonstrated that at baseline, MDS patients had very significant impairment in most of the functioning scores, and the patients who achieved a complete response/partial response with ESAs had significant improvement in domains such as global QoL and fatigue, as compared to those who did not respond. Stasi et al (2005) used the FACT-An scale to demonstrate similar improvements in QoL with haemoglobin increase using Darbepoetin alfa. An earlier systematic review of QoL and use of red cell transfusion in MDS identified only small studies with heterogeneous use of QoL instruments, and poorly defined transfusion protocols (Pinchon et al, 2009); and most published studies have applied general validated instruments to measure QoL, including the EQ-5D, EORTC QLQ-C30 and FACT-Fatigue/Anaemia (Rabin et al, 2001). 
Our study was small and designed as a first feasibility trial in an out-patient setting, with pragmatically defined inclusion and exclusion criteria, and some baseline imbalances were noted, as expected. The predefined feasibility threshold for haemoglobin difference $(20 \mathrm{~g} / \mathrm{L})$ was not quite reached; nonetheless, the difference in haemoglobin was highly statistically, and possibly clinically, significant. Thirty-four, but not all, participants received at least one transfusion during the trial and were included in the 'compliance to treatment threshold' analysis. Repeated measurements on the same participant has not been accounted for in the analysis, as it was not considered appropriate for a small-scale feasibility trial. We also acknowledge that outcomes assessors were not blinded in this study and that reasons were not collected on why patients were not consented, which may have helped further understand rates of enrolment. Finally, we recognise that our trial protocol is based on thresholds for haemoglobin concentration, which may not directly relate to management in some patients which may be individualized based on symptoms.

In summary, research is required in order to evaluate the comparative and cost-effectiveness of different transfusion policies in MDS. All randomized trials of red cell transfusions to date have been undertaken on inpatients, not outpatients (Carson et al, 2018) and few studies have specifically evaluated an older population (Thein et al, 2009). Studies need to consider the associated risks of volume and/or iron overload and infection, as well as other potential transfusion complications in groups of patients allocated to more intensive transfusion schedules, in addition to the inconvenience of lengthy visits to transfusion outpatient departments. On the other hand, reduced overall survival that has been suggested in MDS patients with haemoglobin concentrations $<80 \mathrm{~g} / \mathrm{L}$ in females and $<90 \mathrm{~g} / \mathrm{L}$ in males mostly due to cardiac deaths (de Swart et al, 2019) makes further study into potential benefits (including QoL) for higher haemoglobin thresholds warranted.

\section{Conflicts of interests`}

There are no conflicts of interest

\section{Acknowledgments}

The authors would like to thank all the hospital staff and research teams who helped conduct this trial and all the participants who agreed to take part. This study was supported by the NHS Blood and Transplant Clinical Trials Unit, including: Gillian Powter, Claire Foley, Claire Dyer, Charlotte Llewelyn, Cara Hudson, Joanna Bunnett and Agne Zarankaite. The study was adopted onto the UK's National Institute for Health Research (NIHR) Clinical Research Network Portfolio. This manuscript is independent research funded by NHS Blood and Transplant. The views expressed in this publication 
are those of the author(s) and not necessarily those of NHS Blood and Transplant. We also thank Adrian Newland, Paul White, Gavin Murphy, Michael Greaves, Keith Wheatley, and Marc Turner (the data and safety monitoring committee). Individual participant data that underlie all published trial results will be available upon request to NHSBT CTU after de-identification. Data will be shared to achieve the aims in the approved proposal.

\section{Participating Sites and investigators}

Royal Bournemouth Hospital: Dr Sally Killick, Louise Wallis, Taslima Rabbi, Monica Serrano, Rachel Williams, Dr Joe Chacko, Julia Darlow, Lucy Watson, Kelli Earley, Naomi Haas, Lois Woods, Carla Dimitriu, James Croft, Ana Carvalhosa, Christine Clarke, Tim Hickish, Christina Penny

Great Western Hospital: Dr Alex Sternberg, Tim Owen, Cerila Parajes, Chanelle Meyer, Jan Dodge, Sue Meakin, Donna Lake

Aberdeen Royal Infirmary: Dr Dominic Culligan, Helen Fletcher, Hazel Forbes, Nicola Johannesson, Dr Gordon Taylor, Jill Tomlinson, Ann Shaw, Dr Maria Ratcliffe, Dr Mariella Lamacchia,Professor Mark Vickers, Dr Caroline Duncan,Dr Paraskevi Untiveros,Dr Adetomilola Olaiya, Dr Jane Tighe, Dr Gavin Preston, Dr Mehmood Zaidi, Dr Alastair Lawrie, Dr Charlotte Robertson, Dr Haifaa Saadi, Uzunma Onyeakazi

St. James' Hospital, Leeds: Dr Marina Karakantza \& Professor David Bowen, Dr Rohini Radia, Thomas Father, Katherine Stainthorp, Steward Mc Connell, Terry Booth, Catherine Langton, Clare Howcroft, Ismail Saddiq,

Nottingham City Hospital: Dr Emma das Gupta \& Dr Jennifer Byrne, Jo Lindsey-Hill, Denise Badder, Melanie Jones, Raj Pol,

Churchill Hospital, Oxford: Professor Paresh Vyas, Dr Adam Mead, Dr Andrew Peniket, Rachel Bancroft, Sally Springett, Shobana Yoganayagam, Louisa Gray, Heather Friesen, Katrin Wardle,

Birmingham Heartlands Hospital: Dr Vidhya Murthy, Dr Guy Pratt, Dr. Bhuvan Kishore, Dr Georgina Mayer, Dr Emmanouil Nikolousis, Dr Neil Smith, Dr Richard lovell, Dr Charalampos Kartsios, Dr Joanne Ewing, Dr Matthew Lumley, Dr Jahanzeb Khawaja, Dr Majed Ali, Dr David Sutton, Dr Duncan Murray, Dr Donald Milligan, Sundip Dhani (nee Sohanpal), Mary O'Sullivan, James Whitehouse, Anne Schumacher, Rosemarie Enstone, Alison Hardy, Melanie Kelly,

Freeman Hospital, Newcastle: Dr Jonathan Wallis, Lauren Boal, Mark Davies, Ruth Latter, Joanne Wincup, Steven Ellis, Sonia Poolan, Mark Birt, Emily Watts, Andrew Charlton, Hazel Forsyth, Louisa Waring, Julie Twohig, Helen Marr, Anne Lennard, Gail Jones, Tobias Menne, Nicola Redding, Susan Jones, Kate Robinson

Salisbury Hospital: Dr Effie Grand, Dr Jonathan Cullis, Dr Freya Collins, Dr Louise Gamble, Jenny Brown, Saffron Tudgay, Sarah Salisbury, Siju Mathew,Nicole Tipler, Tracey Parker, Emma Stobie, Michele Tribbeck

Royal Derby Hospital: Dr Sangam Hebballi, Dr Christopher Millar, Dr David Allotey, Dr Jai Lala, Nicole McGee (nee Isitt), Jo Chmeil, Lianne Hufton, Sarah Dawson,

Capital \& Coast District Health Board, Wellington: Dr Rob Weincove, Dr. Duncan Smyth, Dr Hubertus Buyck, Dr Jina Hayden, Dr Anup George, Israel Baluwala, Dr Matthew Wheeler, Lisa Daysh, Dr Owain Williams, Susan Millmow, Rebecca Miles, Sushi Geller, Maureen Blakemore, Ann Hargreaves, Gina Hayden

Clayton Medical Centre, Monash: Dr Zoe McQuilten, Allison Mo, Matt Van Dam, Micheleine Uhe, Tishya Indran, Jonathan Wong, Liz Coughlin

New Cross Hospital, Wolverhampton: Dr Alan MacWhannell, Claire Beardsmore, Lucy Lunn, Sharon Pearson, Simon Shaw

Northampton General Hospital: Dr Jane Parker, Angela Bowen, Andrea Jones, Matthew Player

\section{Funding}


Funding was provided by grants awarded by NHSBT R\&D, the Australian and New Zealand Society of Blood Transfusion (ANZSBT) and the Wellington Division of the New Zealand Cancer Society.

\section{Authorship contributions}

Designed study: SS, RB, DB, JC, YL; Collected data: SK, ZM, MK, RW, HS, EW; Database: RH, VH; Statistics: LP, HT; Trial management: AD. All authors reviewed manuscripts. 


\section{References}

1. Cogle CR, Craig BM, Rollison DE, List AF, (2011) Incidence of the myelodysplastic syndromes using a novel claims-based algorithm: high number of uncaptured cases by cancer registries. Blood;117:71215.

2. Sekeres MA, Schoonen WM, Kantarjian H, List A, Fryzek J, Paquette R, Maciejewski JP et al. (2008). Characteristics of US patients with myelodysplastic syndromes: results of six cross-sectional physician surveys. J Natl Cancer Inst.;100:1542-51

3. Malcovati L, Della Porta MG, Strupp C, Ambaglio I, Kuendgen A, Nachtkamp K, Travaglino E, Invernizzi R, Pascutto C, Lazzarino M, Germing U, Cazzola M. (2011) Impact of the degree of anemia on the outcome of patients with myelodysplastic syndrome and its integration into the WHO classification-based Prognostic Scoring System (WPSS). Haematologica; 96:1433-1440

4. de Swart L, Smith A, Fenaux P, Symeonidis A, Hellström-Lindberg E, \& Sanz G, Cermak J, Georgescu O, Germing U, MacKenzie M, Beyne-Rauzy O, Malcovati, L. (2011) Management of 1000 patients with low- and intermediate-1 risk myelodysplastic syndromes in the European LeukemiaNet MDS Registry. Leukemia Research, 35, Supplement 1:S3.

5. Jadersten M, Montgomery SM, Dybedal I, Porwit-MacDonald A, Hellstrom-Lindberg E. (2005) Long-term outcome of treatment of anemia in MDS with erythropoietin and G-CSF. Blood.;106:80311.

6. Stauder R, Yu G, Koinig KA, Bagguley T, Fenaux P, Symeonidis A, Sanz G, Cermak J, Mittelman M, Hellström-Lindberg E, Langemeijer S, Holm MS, Mądry K, Malcovati L, Tatic A, Germing U, Savic A, van Marrewijk C, Guerci-Bresler A, Luño E, Droste J, Efficace F, Smith A, Bowen D, de Witte T. (2018) Health-related quality of life in lower-risk MDS patients compared with age- and sex-matched reference populations: a European LeukemiaNet study. Leukemia.; 32(6):1380-1392.

7. Mo A, McQuilten ZK, Wood EM, Weinkove R. (2017). Red cell transfusion thresholds in myelodysplastic syndromes: a clinician survey to inform future clinical trials. Internal medicine journal;47:695-8

8. Docherty AB, O'Donnell R, Brunskill S, Trivella M, Doree C, Holst L, Walsh T, Stanworth SJ. Effect of restrictive versus liberal transfusion strategies on outcomes in patients with cardiovascular disease in a non-cardiac surgery setting: systematic review and meta-analysis BMJ 2016; 352 :i1351

9. Buckstein R, Alibhai SM, Lam A. (2011) The health-related quality of life of MDS patients is impaired and most predicted by transfusion dependence, hemoglobin and age. Leukemia Research.;35, Supplement 1: S55-S56.

10. Carson JL, Stanworth SJ, Alexander JH, Roubinian N, Fergusson DA, Triulzi DJ, Goodman SG, Rao SV, Doree C, Hebert PC. (2018). Clinical trials evaluating red blood cell transfusion thresholds: An updated systematic review and with additional focus on patients with cardiovascular disease.

American Heart Journal;200:96-101

11. Lin Y, Buckstein R. (2018). Outpatient transfusions: time to study what matters to patients. Transfusion;59:1887-1890 
12. Swerdlow S.H., Campo E., Harris N.L. (2008). WHO Classification of Tumours of Haematopoietic and Lymphoid Tissues. IARC: Lyon.

13. Carson JL, Carless PA, Hebert PC. (2012). Transfusion thresholds and other strategies for guiding allogeneic red blood cell transfusion. The Cochrane database of systematic reviews; 4:CD002042

14. van Hout B, Janssen MF, KohImann T, Busschbach J, Golicki D, Lloyd A, Scalone L, Kind P, Pickard AS. (2012). Interim scoring for the EQ-5D-5L: Mapping the EQ-5D-5L to EQ-5D-3L value sets. Value in Health.15(5):708-15.

15. Maringwa JT, Quinten C, King M, Ringash J, Osoba D, Coens C, Martinelli F, Vercauteren J, Cleeland CS, Flechtner H, Gotay C, Greimel E, Taphoorn MJ, Reeve BB, Koch JS, Weis J, Smit EF, van Meerbeeck JP, Bottomley A; EORTC PROBE project and the Lung Cancer Group. (2011). Minimal important differences for interpreting health-related quality of life scores from the EORTC QLQ-C30 in lung cancer patients participating in a randomized controlled trials. Support Care Cancer.;19(11):1753-60.

16. Luo N, Johnson J, Coons SJ. (2010). Using Instrument-Defined Health State Transitions to Estimate Minimally Important Differences for Four Preference-Based Health-Related Quality of Life Instruments. Med Care;48(4):365-71.

17. Cocks K, King MT, Velikova G, Martyn St-James M, Fayers PM, Brown JM. (2011). Evidencebased guidelines for determination of sample size and interpretation of the European Organisation for the Research and Treatment of Cancer Quality of Life Questionnaire Core 30. J Clin

Oncol.;29(1):89-96

18. Nilsson-Ehle $H$, Birgegård $G$, Samuelsson J, Antunovic $P$, Astermark J, Garelius $H$, Engström LM, Kjeldsen L, Nilsson L, Olsson A, Skov-Holm M, Wallvik J, Gulbrandsen N, Hellström-Lindberg E (2011). Quality of life, physical function and MRI T2* in elderly low-risk MDS patients treated to a haemoglobin level of $\geq 120 \mathrm{~g} / \mathrm{L}$ with darbepoetin alfa \pm filgrastim or erythrocyte transfusions. Eur J Haematol.;87(3):244-52.

19. Jansen AJ, Essink-Bot ML, Beckers EA, Hop WC, Schipperus MR, Van Rhenen DJ. (2003). Quality of life measurement in patients with transfusion-dependent myelodysplastic syndromes. $\mathrm{Br}$ J Haematol. 121(2):270-4.

20 Lezin ES, Karafin MS, Bruhn R, Chowdhury D, Qu L, Bialkowski W, Merenda S, D'Andrea P, McCalla AL, Anderson L, Keating SM, Stone M, Snyder EL, Brambilla D, Murphy EL, Norris PJ, Hilton JF, Spencer BR, Kleinman S, Carson JL; NHLBI Recipient Epidemiology and Donor Evaluation Study (REDS)-III Program.. (2019). Therapeutic impact of red blood cell transfusion on anemic outpatients: the RETRO study. Transfusion; 59:1934-1943

21. Caocci G, Baccoli R, Ledda A, Littera R, La Nasa G. (2007). A mathematical model for the evaluation of amplitude of hemoglobin fluctuations in elderly anemic patients affected by myelodysplastic syndromes: correlation with quality of life and fatigue. Leuk Res; 31(2):249-52.

22. Hellstrom-Lindberg E, Gulbrandsen N, Lindberg G, Ahlgren T, Dahl IM, Dybedal I, Grimfors G, Hesse-Sundin E, Hjorth M, Kanter-Lewensohn L, Linder O, Luthman M, Löfvenberg E, Oberg G, Porwit-MacDonald A, Rådlund A, Samuelsson J, Tangen JM, Winquist I, Wisloff F; Scandinavian MDS Group. (2003). A validated decision model for treating the anaemia of myelodysplastic syndromes 
with erythropoietin + granulocyte colony-stimulating factor: significant effects on quality of life. $\mathrm{Br} J$ Haematol;120:1037-46.

23. Stasi R, Abruzzese E, Lanzetta G, Terzoli E, Amadori S. (2005). Darbepoetin alfa for the treatment of anemic patients with low- and intermediate-1-risk myelodysplastic syndromes. Ann Oncol;16:1921-7

24. Pinchon DJ, Stanworth SJ, Doree C, Brunskill S, Norfolk DR. (2009). Quality of life and use of red cell transfusion in patients with myelodysplastic syndromes. A systematic review. Am J Hematol.;84:671-7.

25. Rabin R, de Charro F. (2001). EQ-5D: a measure of health status from the EuroQoL Group. Ann Med.;33:337-43

26. Thein M, Ershler WB, Artz AS, Tecson J, Robinson BE, Rothstein G, Liede A, Gylys-Colwell I, Lu ZJ, Robbins S.. (2009). Diminished Quality of Life and Physical Function in Community-Dwelling Elderly With Anemia. Medicine;88:107-14. 
Table I Baseline characteristics, data are $\mathrm{n}(\%)$ or median (interquartile range) as appropriate

\begin{tabular}{|c|c|c|c|c|}
\hline & Restric & ve $(n=20)$ & Libera & $(n=18)$ \\
\hline Male & 13 & $(65)$ & 14 & $(78)$ \\
\hline Age (years) at registration & 79 & $(69-82)$ & 80 & $(69-84)$ \\
\hline $\begin{array}{l}\text { Ethnicity } \\
\text { White } \\
\text { Black } \\
\text { Chinese/East Asian } \\
\text { Hispanic } \\
\text { Asian } \\
\text { Mixed } \\
\text { Other } \\
\text { Not stated }\end{array}$ & $\begin{array}{r}18 \\
0 \\
0 \\
0 \\
1 \\
0 \\
0 \\
1\end{array}$ & $\begin{array}{l}(90) \\
(0) \\
(0) \\
(0) \\
(5) \\
(0) \\
(0) \\
(5)\end{array}$ & $\begin{array}{r}14 \\
1 \\
0 \\
0 \\
0 \\
0 \\
3 \\
0\end{array}$ & $\begin{array}{l}(78) \\
(6) \\
(0) \\
(0) \\
(0) \\
(0) \\
(17) \\
(0)\end{array}$ \\
\hline $\begin{array}{l}\text { ECOG status at randomization } \\
0 \\
1 \\
2\end{array}$ & $\begin{array}{r}3 \\
16 \\
1\end{array}$ & $\begin{array}{l}(15) \\
(80) \\
(5)\end{array}$ & $\begin{array}{l}9 \\
8 \\
1\end{array}$ & $\begin{array}{l}(50) \\
(44) \\
(6)\end{array}$ \\
\hline Height $(\mathrm{cm})$ at registration & 166 & $(158-175)$ & 172 & $(160-173)$ \\
\hline Weight $(\mathbf{k g})$ at registration & 76 & $(65-88)$ & 72 & $(70-85)$ \\
\hline $\begin{array}{l}\text { MDS diagnosis* } \\
\text { RCUD-A } \\
\text { RCUD-N } \\
\text { RCUD-T } \\
\text { RARS } \\
\text { RCMD } \\
\text { RCMD-RS } \\
\text { RAEB-1 } \\
\text { RAEB-2 } \\
5 q \\
\text { MDS-U } \\
\text { MPNS } \\
\text { Years dependence on red cells at } \\
\text { registration }\end{array}$ & $\begin{array}{r}3 \\
0 \\
0 \\
2 \\
11 \\
2 \\
0 \\
0 \\
0 \\
1 \\
1 \\
1\end{array}$ & $\begin{array}{l}(15) \\
(0) \\
(0) \\
(10) \\
(55) \\
(10) \\
(0) \\
(0) \\
(0) \\
(5) \\
(5) \\
(1-4)\end{array}$ & $\begin{array}{l}2 \\
0 \\
0 \\
1 \\
7 \\
4 \\
1 \\
1 \\
0 \\
1 \\
1 \\
1\end{array}$ & $\begin{array}{l}(11) \\
(0) \\
(0) \\
(6) \\
(39) \\
(22) \\
(6) \\
(6) \\
(0) \\
(6) \\
(6) \\
(1-2)\end{array}$ \\
\hline $\begin{array}{l}\text { Previous medical history* } \\
\text { Myocardial infarction } \\
\text { New or worsening angina } \\
\text { Stroke } \\
\text { Transient ischemic attack } \\
\text { Red cell alloantibodies } \\
\text { Iron chelation treatment } \\
\text { Prior therapy for MDS } \\
\text { On heart failure medication } \\
\text { On cardiovascular disease } \\
\text { medication }\end{array}$ & $\begin{array}{r}4 \\
0 \\
1 \\
2 \\
5 \\
6 \\
6 \\
7 \\
10\end{array}$ & $\begin{array}{l}(20) \\
(0) \\
(5) \\
(10) \\
(25) \\
(30) \\
(30) \\
(35) \\
(50)\end{array}$ & $\begin{array}{l}2 \\
0 \\
0 \\
1 \\
2 \\
2 \\
5 \\
3 \\
8\end{array}$ & $\begin{array}{l}(11) \\
(0) \\
(0) \\
(6) \\
(11) \\
(11) \\
(28) \\
(17) \\
(44)\end{array}$ \\
\hline $\begin{array}{l}\text { Number of red cell units transfused } \\
\text { per participant in the } 8 \text { weeks prior } \\
\text { to enrolment }\end{array}$ & 5 & $(4-7)$ & 4 & $(4-8)$ \\
\hline $\begin{array}{l}\text { IPSS-R at enrolment } \\
\text { Very Low } \\
\text { Low } \\
\text { Intermediate } \\
\text { High } \\
\text { N/A }\end{array}$ & $\begin{array}{l}5 \\
8 \\
2 \\
1 \\
4\end{array}$ & $\begin{array}{l}(25) \\
(40) \\
(10) \\
(5) \\
(20)\end{array}$ & $\begin{array}{l}2 \\
9 \\
2 \\
3 \\
2\end{array}$ & $\begin{array}{l}(11) \\
(50) \\
(11) \\
(17) \\
(11)\end{array}$ \\
\hline
\end{tabular}

Footnote: MDS diagnosis according to WHO; IPSS reference 
Table II: Standardized Area Under the Curve for the key quality of life outcomes. Data are median (interquartile range)

\begin{tabular}{llll}
\hline & $\begin{array}{l}\text { Restrictive } \\
(\mathbf{n = 2 0})\end{array}$ & $\begin{array}{l}\text { Liberal } \\
(\mathbf{n = 1 8})\end{array}$ & $\begin{array}{l}\text { Overall } \\
(\mathbf{n}=\mathbf{3 8})\end{array}$ \\
\hline $\begin{array}{l}\text { EQ-5D-5L: Descriptive part } \\
\text { (Higher is better) }\end{array}$ & $0.76(0.51-0.81)$ & $0.83(0.69-0.86)$ & $0.78(0.68-0.86)$ \\
$\begin{array}{l}\text { EORTC QLQ-C30: Physical functioning } \\
\text { (Higher is better) }\end{array}$ & $61(50-86)$ & $69(48-94)$ & $68(50-86)$ \\
$\begin{array}{l}\text { EORTC QLQ-C30: Fatigue } \\
\text { (Lower is better) }\end{array}$ & $38(33-54)$ & $34(14-66)$ & $37(21-63)$ \\
$\begin{array}{l}\text { EORTC QLQ-C30: Dyspnoea } \\
\text { (Lower is better) }\end{array}$ & $42(31-64)$ & $25(1-77)$ & $40(12-67)$ \\
$\begin{array}{l}\text { EORTC QLQ-C30: Global health scores } \\
\text { (Higher is better) }\end{array}$ & $63(60-75)$ & $70(53-87)$ & $68(56-76)$ \\
\hline
\end{tabular}




\section{Figures legends}

Figure 1:

Study Schema and algorithm for transfusion

Figure 2:

CONSORT diagram

\section{Figure 3:}

Graph of mean ( $\pm S D$ ) haemoglobin by week for all randomized participants by treatment arm. This uses all haemoglobins reported on study visits (i.e. day $0,7,28$, 56 and 84 ) and all pre-transfusion haemoglobins (i.e. the haemoglobins reported prior to each transfusion).

Figure 4

A bubble plot to display timing and volume of red cell transfusions before and after day of randomization in each arm 
Figure 1: Study Schema and algorithm for transfusion

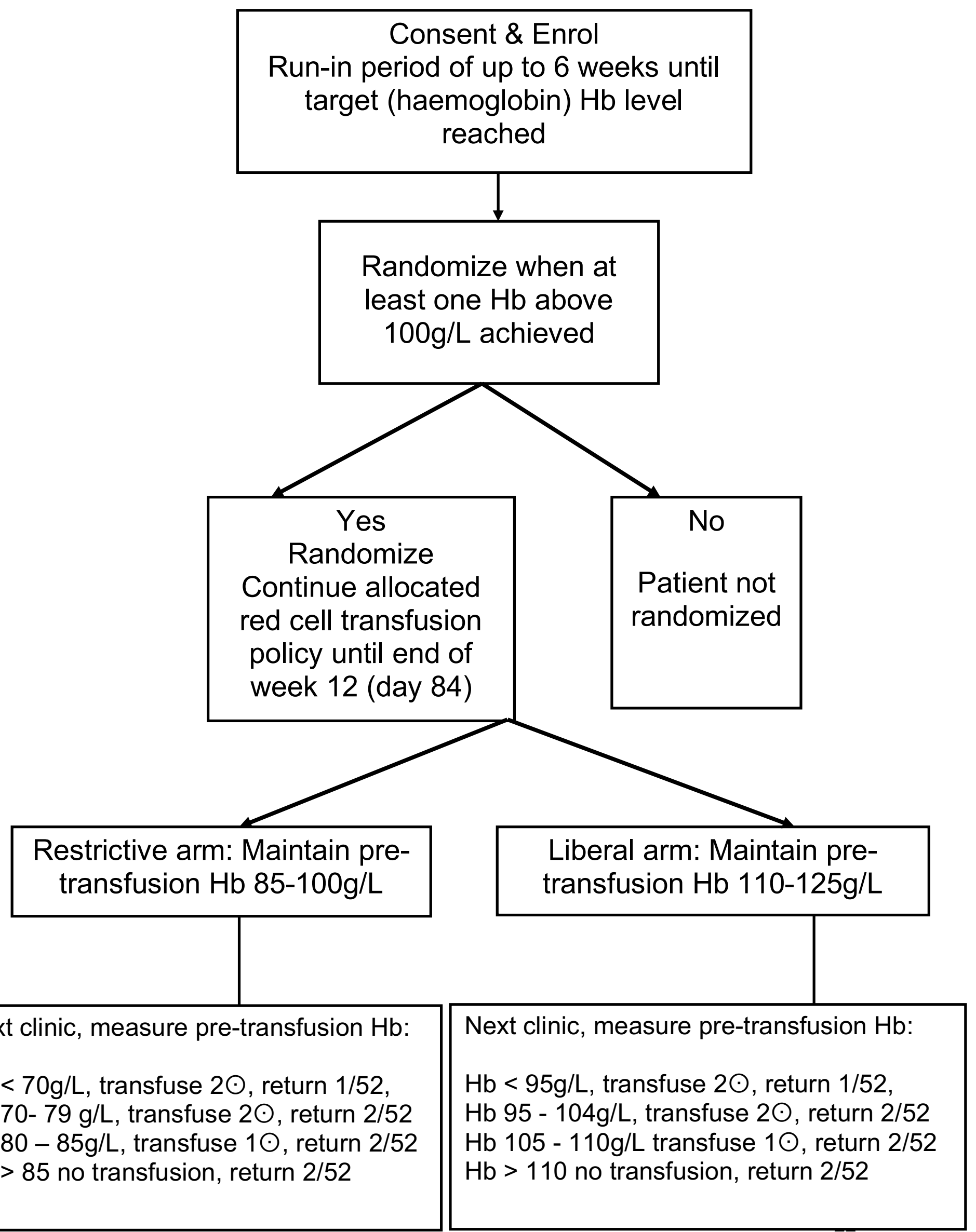


Figure 2: CONSORT diagram 
Figure 3: Graph of mean (ISD) haemoglobin by week for all randomized participants by treatment arm. This uses all haemoglobins reported on study visits (i.e. day 0,7 , 28, 56 and 84) and all pre-transfusion haemoglobins (i.e. the haemoglobins reported prior to each transfusion).

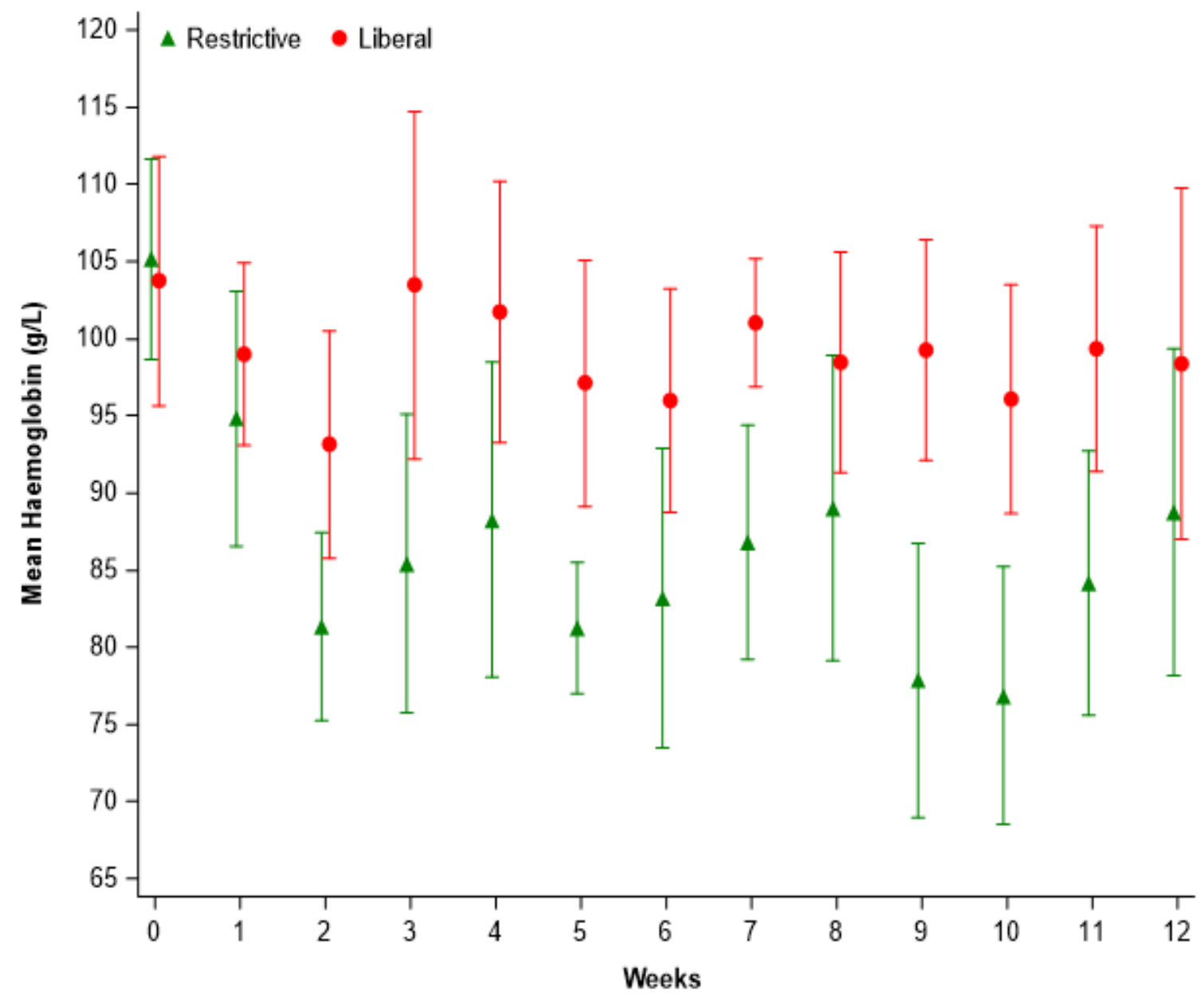

The number of haemoglobin measurements included at each time point

\begin{tabular}{|r|c|c|c|c|c|c|c|c|c|c|c|c|c|}
\hline Randomization arm & $\mathbf{0}$ & $\mathbf{1}$ & $\mathbf{2}$ & $\mathbf{3}$ & $\mathbf{4}$ & $\mathbf{5}$ & $\mathbf{6}$ & $\mathbf{7}$ & $\mathbf{8}$ & $\mathbf{9}$ & $\mathbf{1 0}$ & $\mathbf{1 1}$ & $\mathbf{1 2}$ \\
\hline Restrictive & 27 & 12 & 3 & 12 & 15 & 7 & 5 & 11 & 11 & 7 & 8 & 7 & 12 \\
\hline Liberal & 28 & 14 & 8 & 12 & 16 & 10 & 10 & 10 & 14 & 13 & 9 & 11 & 11 \\
\hline
\end{tabular}


Figure 4: A bubble plot to display timing and volume of red cell transfusions before and after day of randomization

Bubble plot showing for each participant when RBC transfusions were received, in the 6 weeks pre randomisation and the 12 weeks post randomisation

The size of the bubble indicates the number of units which were transfused (smallest=1 unit, largest=3 units)

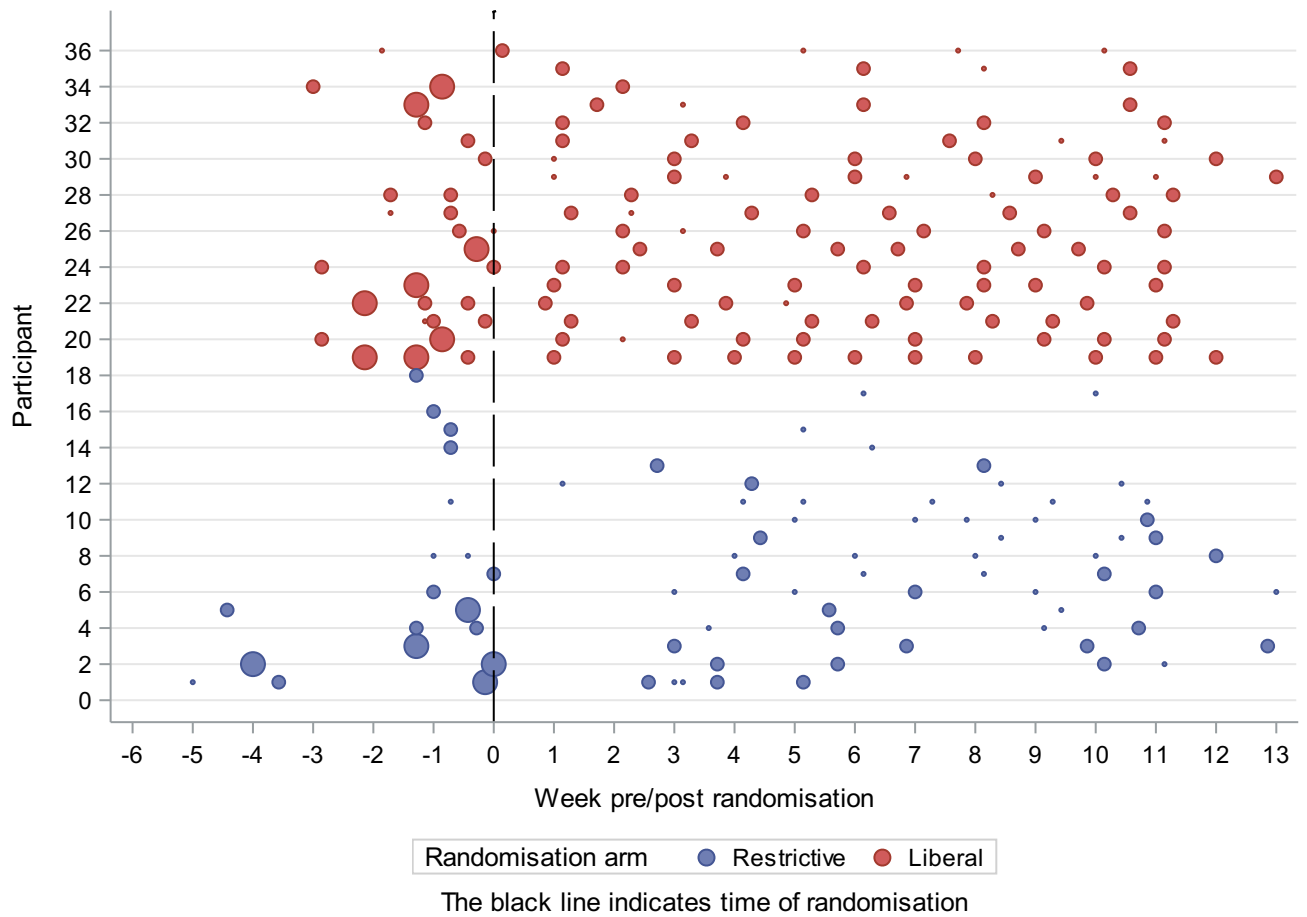


